\title{
Perceval, eine Auseinandersetzung
}

\author{
F. Burkhardt
}

Korrespondenz:

Dr. med. Franziska Burkhardt

Obere Gasse 12 a

CH-4144 Arlesheim
Eigentlich wollte ich von meiner Suche nach vorchristlichen, matriarchalen Bildern in Perceval berichten, von den Farben Weiss, Rot und Schwarz, den Farben der dreifachen Göttin, von Perceval, der den roten Ritter tötete und zu demselben wird, von Blanchefleur, der Jungfrau im purpurroten Mantel, welche in ihrer verödeten Burg den roten Perceval zu ihrem Geliebten erwählt, vom Reichtum, welcher nach der gemeinsamen Nacht in die Burg zurückkehrt. Ich wollte über Jungfrauen schreiben, die immer wieder unter einer grossen Eiche, neben einer heilsamen Quelle sitzend, anzutreffen sind; von Perceval, welcher zuerst ein rotes, dann ein schwarzes und schliesslich ein weisses Pferd reitet, und dessen Rüstung von Rot zu Silber (Weiss) und dann zu Schwarz wechselt. Vom Fischerkönig wollte ich erzählen, welcher in einen Mantel so schwarz wie eine Brombeere mit einem rubinfarbenen Saum gekleidet auf dem

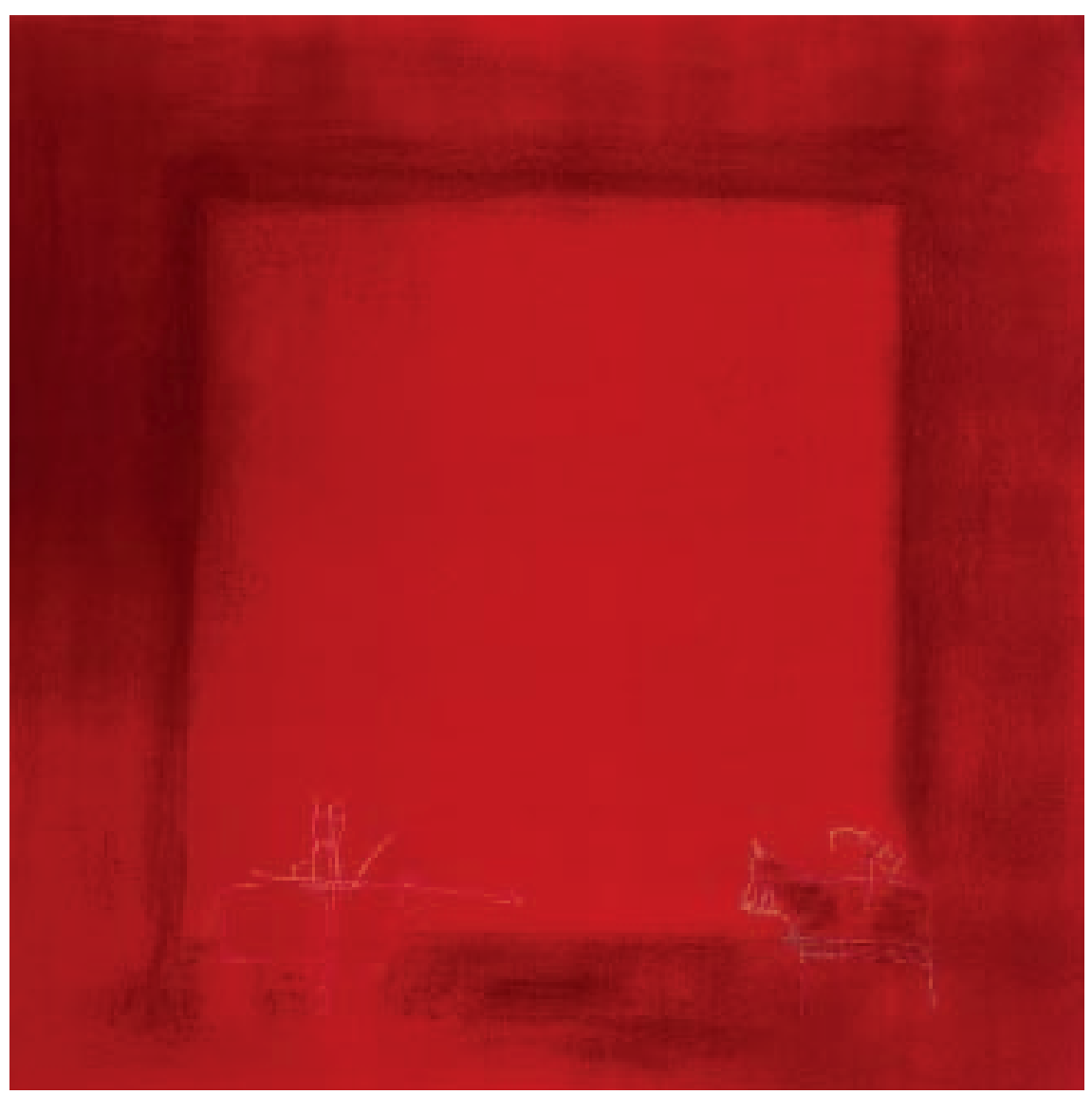

Perceval, der rote Ritter. Monotypie, $60 \times 50$ cm, 2002 .

Fluss zwischen den Welten Kahn fährt und weder leben noch sterben kann; von Sigune, Kundrie und der Gralsjungfrau, die Perceval verdammen und leiten; vom weissen Ritter, welcher die Liebesfurt bewacht; vom schwarzen Ritter in der Grabkapelle und dem Ritter im Sarkophag. Von den geheimnisvollen Schildern in allen Farben wollte ich reden und schliesslich vom Gral, der uralten Quelle der Wiedergeburt und des ewigen Lebens.

Nachdenken wollte ich über diese Bilder und Gestalten sowie ihre Bezüge zu alten, vorhistorischen, vielleicht matriarchalen Kulturen; wie sie, eingebettet in eine christlich umgestaltete Rahmenhandlung, überlebten und auch immer wieder in unseren Märchen anzutreffen sind; über Percevals erstes Vergehen, das Verlassen der Mutter, das nur aus einer alten sippenrechtlichen matriarchalen Kultur verstanden werden kann. Ein Schritt, welcher in unserer modernen westlichen Welt erst die angestrebte individuelle Entwicklung ermöglicht.

Doch das Schicksal verstrickte mich selber auf unerwartete Weise mit der Percevalgeschichte. Begonnen hat alles ganz harmlos mit einer Diskussion, welche ich übrigens wieder vergass, über Parzival und einen Autor, welcher die ganze Handlung als historisch annimmt und in der Eremitage bei Arlesheim (BL), meinem Wohnort, ansiedelt, eine Auffassung, welche ich bis heute nicht teile. Geraume Zeit später führte ich mein Pferd einen steilen Pfad in die Eremitage hinunter. Neben einer riesigen alten Rotbuche war mir Parzival urplötzlich ganz nahe, als wäre ich selber von der Geschichte betroffen oder betroffen gewesen. Daraufhin beschäftigte ich mich mit den verschiedenen Quellen. Bis anhin hatte mich diese Geschichte, abgesehen von einem Jugendroman, welchen ich in der Kindheit las, nicht interessiert. Bei der Lektüre des Percevals von Chrestien de Troyes entstanden in mir sofort Bilder, welche ich künstlerisch umsetzte. Ich fand zu einer Fortsetzung meiner Farb- und Formensprache, nach der ich schon lange gesucht hatte. Zwei Monate vertiefte ich mich in Rot. Dann schlug ich gegen eine geöffnete Vitrinentüre, deren Glas auf meinem nackten Rücken zersplitterte. Trotz wechselnden Beschwerden im Thoraxbereich wurde einer kleinen Wunde zwischen den Schulterblättern keine Bedeutung zugemessen. Eine forcierte Test- 


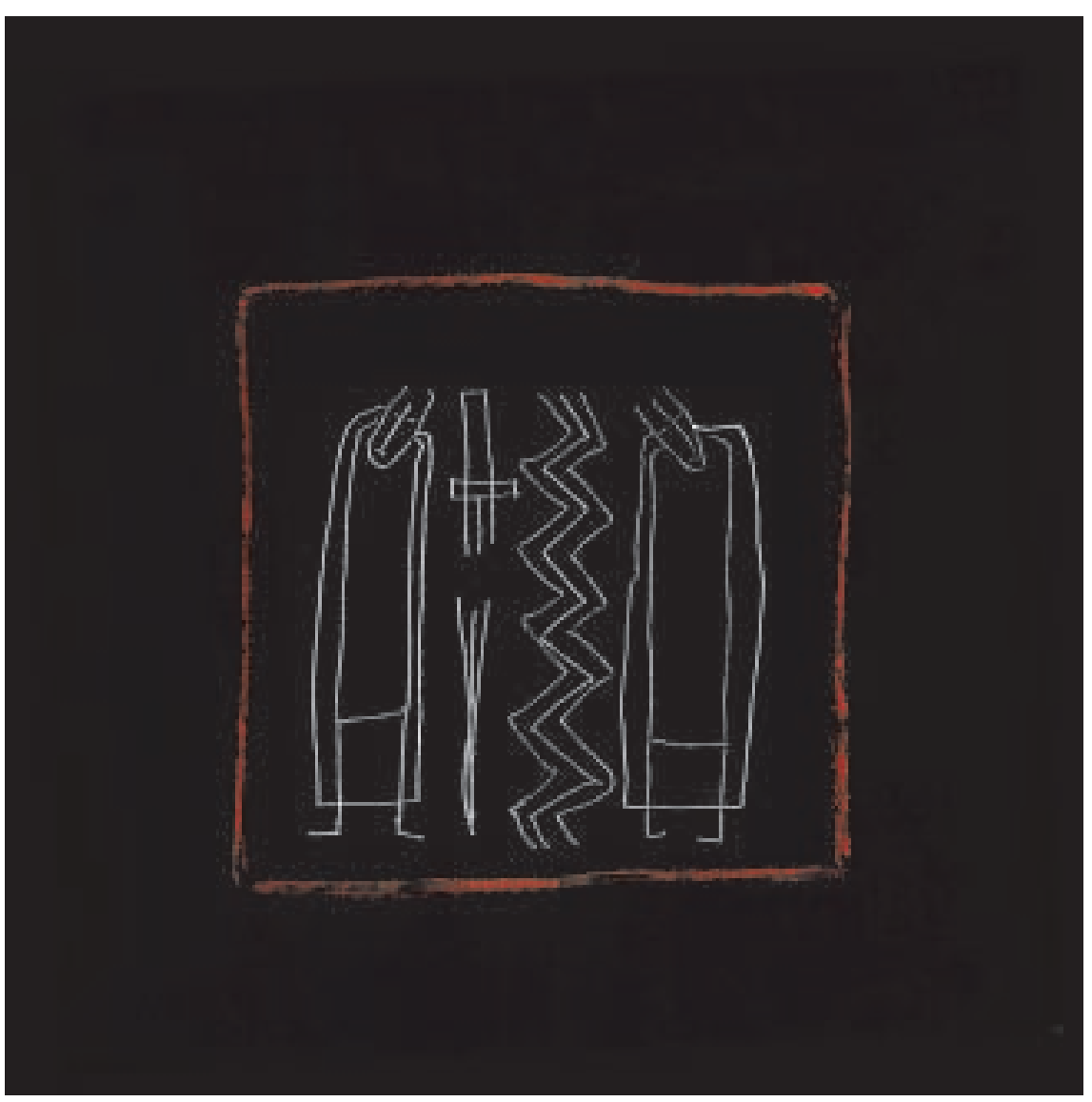

Der Fischerkönig. Monotypie, $60 \times 50$ cm, 2002 .

fahrt mit dem Rad nach Basel ergab eine normale Leistungsfähigkeit. Den Druck im oberen Brustbereich erklärte ich mit Verspannungen. Nach zehn Tagen ertastete man unter der inzwischen geschlossenen Wunde einen Glassplitter. Bei der chirurgischen Entfernung stellte sich dieser als senkrecht gegen den Brustraum stechend heraus. Die anschliessende Röntgenkontrolle ergab überraschend einen Pneumothorax, der eine Drainage notwendig machte. Nachträglich musste ich annehmen, dass anfangs wohl die ganze linke Lunge kollabiert war.

In der erzwungenen Ruhe ergaben sich mir merkwürdige Zusammenhänge. In der Zeit vor der Verletzung setzte ich mich intensiv mit Rot und Percevals Kampf mit dem roten Ritter auseinander. Dann der Glassplitter, fast drei Zentimeter lang, schmal und spitz wie eine Pfeilspitze, die Verletzung zwischen den Schulterblättern, eine fast mythologische Stelle, unter anderem war Siegfried hier verwundbar. In der kritischen Zeit des Pneumothorax dominierte Schwarz. Es entstanden die Bilder vom Fischerkönig, schwebend zwischen Leben und Tod, von Sigune mit dem toten Schionatulander im Schosse und vom schwarzen Ritter in der Grabkapelle. In dieser Zeit träumte ich auch von einem kleinen naturschwammartigen Pferdchen, das mir in den Händen zunehmend schrumpfte, für mich besonders bedrohlich, da ich früher von einem kleinen blaugrünen Pferdchen geträumt hatte, welches unter meiner Pflege zu einem Riesenpferd herangewachsen war.

Erst nach der Diagnose, im Spital, wurde mir der Bezug zwischen dem schrumpfenden Pferdchen und meiner Lunge sowie den dunklen Bildern und meiner eigenen, in dieser Zeit kritischen, Situation bewusst.

Die Bilder der Parzivalserie sowie Arbeiten zum Nordland, seinen Landschaften, Mythen und dem Nordlicht sind in der Ausstellung «Mythische Reisen», Bilder und Skulpturen von Franziska Burkhardt im Kloster Dornach zu sehen.

\section{Ausstellung im Kloster Dornach vom 3. bis 24. November 2002}

Kloster Dornach, Amtshausstrasse 7, 4143 Dornach (SO)

\section{Vernissage}

Samstag, 2. November 2002, 16.00 Uhr

\section{Führungen mit der Künstlerin}

Sonntag, 3. November, 16.00 Uhr, Perceval

Dienstag, 12. November, 18.30 Uhr

Sonntag, 17. November, 16.00 Uhr, Nordland

Dienstag, 19. November, 18.30 Uhr

Samstag, 23. November, 16.00 Uhr

\section{Öffnungszeiten}

Samstag, Sonntag, 15.00-18.00 Uhr

Dienstag, 17.00-20.00 Uhr

Während der Öffnungszeiten des Cafés Klösterli ist die Ausstellung auch zugänglich:

Mittwoch, 14.00-17.00 Uhr

Sonntag, 10.00-16.00 Uhr 